\title{
Economia brasileira e condições de vida e de trabalho da população - reações à crise internacional ${ }^{\dagger}$
}

\author{
Solange de Cássia Inforzato de Souza* \\ Álvaro Manoel ${ }^{* *}$
}

\begin{abstract}
RESUMO - Este ensaio tem como objetivo refletir sobre as condições de vida e de trabalho no contexto das transformações recentes da economia brasileira e da crise internacional. A despeito dos mecanismos utilizados pelo Brasil para o amortecimento da crise internacional e seus efeitos menos contundentes no mercado de trabalho e nas condições de vida da sua população, é preciso ponderar pelos constrangimentos que persistem na economia brasileira, que em sua essência parecem estar na responsabilidade fiscal, nas taxas domésticas de juros e nas práticas que repercutem na apreciação cambial.
\end{abstract}

Palavras-chave: Crescimento econômico. Crise internacional. Trabalho. Condições de vida.

\section{INTRODUÇÃO}

As transformações da economia brasileira na última década, especialmente em sua segunda metade, refletiram sobre as condições de vida e de trabalho da sua população, materializadas na redução da desigualdade da renda pessoal, crescimento da renda das camadas mais pobres, ascensão da classe média e recuperação do mercado de trabalho, indicando certo distanciamento da severidade da crise internacional que abalou as economias do mundo no último triênio.

As experiências, no plano doméstico, do regime macroeconômico ancorado nas metas de inflação, responsabilidade fiscal e câmbio flutuante do pós-1999, do mecanismo robusto de transferência condicionada de renda pós-2003, da política de valorização do salário mínimo e formalização do emprego, aliadas ao plano externo favorável pelo crescimento das exportações e choque positivo dos termos de troca até 2008 , em grande parte indicaram a relevância dos anos 2000 para a sociedade brasileira.

Até o início da década o crescimento fez-se de modo descontínuo, revigorando-se pós-2006. Os principais aspectos podem ser resumidos: maior acesso de famílias de menor poder aquisitivo a bens duráveis, que mantiveram o vigor do ciclo de crescimento até 2008;

† Artigo originalmente publicado na Revista Atlantide, Dal posto al percorso. Dove va il lavoro? Milão, v. 22, 2011.

* Doutora em Educação pela Pontifícia Universidade Católica de São Paulo. É professora associada da Universidade Estadual de Londrina. Endereço eletrônico: solangecassia@uol.com.br.

** Economista Sênior do Departamento de Política Econômica e Dívida do Banco Mundial. Endereço eletrônico: amanoel@worldbank.org. 
aumento do salário mínimo real e do crédito; e a viabilização do acesso de famílias menos favorecidas ao consumo com prazos maiores.

A conjuntura internacional favorável possibilitou o aumento das exportações, ganhos importantes nos termos de troca e o crescimento da entrada de capital, que permitiu o aumento do consumo interno com taxas internas de poupança relativamente reduzidas. A expansão das exportações se deu tanto em termos das tradicionais commodities primárias, quanto dos produtos manufaturados, com exceção de 2009, mas efetivamente centrada nos produtos básicos (Tabela $1)$.

TABELA 1 - EXPORTAÇÕES BRASILEIRAS POR FATOR AGREGADO: 2006-2010

\begin{tabular}{|c|c|c|c|c|c|c|c|c|c|}
\hline \multirow[b]{2}{*}{ Anos } & \multicolumn{3}{|c|}{ Produtos básicos } & \multicolumn{3}{|c|}{ Produtos manufaturados } & \multicolumn{3}{|c|}{ Exportações totais } \\
\hline & $\begin{array}{l}\text { Valor (US\$ } \\
\text { milhões) }\end{array}$ & $\begin{array}{c}\Delta \% \\
\text { anual }\end{array}$ & $\begin{array}{c}\text { Participação } \\
\% \text { no total }\end{array}$ & $\begin{array}{c}\text { Valor (US\$ } \\
\text { milhões) }\end{array}$ & $\begin{array}{c}\Delta \% \\
\text { anual }\end{array}$ & $\begin{array}{c}\text { Participação } \\
\% \text { no total }\end{array}$ & $\begin{array}{c}\text { Valor } \\
\text { (US\$ milhões) }\end{array}$ & $\begin{array}{c}\Delta \% \\
\text { anual }\end{array}$ & $\begin{array}{c}\text { Total } \\
\%\end{array}$ \\
\hline 2006 & 40.272 & 16,9 & 29,2 & 74.699 & 15,6 & 54,4 & 137.471 & 17,1 & 100 \\
\hline 2007 & 51.596 & 28,1 & 32,1 & 83 & 11,9 & 52,3 & 49 & 19 & 100 \\
\hline 2008 & 73.028 & 41,5 & 36,9 & 92.683 & 10,4 & 46,8 & 197.942 & 23,1 & 100 \\
\hline 2009 & 61.957 & $-15,2$ & 40,5 & 67.349 & $-27,3$ & 44 & 152.995 & $-22,7$ & 100 \\
\hline $2010^{*}$ & 64.729 & 36,6 & 44,7 & 57.260 & 19,8 & 39,5 & 144.929 & 29,6 & 100 \\
\hline
\end{tabular}

FONTE: Ministério do Desenvolvimento, da Indústria e do Comércio Exterior - MDIC - SECEX. Brasil (2010) NOTA: * Referente a Janeiro-Setembro de 2010.

Os novos segmentos de mercado proporcionados pela ascensão da classe $\mathrm{C}$, ou classe média brasileira, dinamizaram aqueles setores, especialmente industriais que, em face da competição externa e de suas dificuldades de reestruturação e em ganhar competitividade, mostravam-se relativamente constrangidos. No entanto, quando a economia retomava seu ciclo de crescimento, as dificuldades enfrentadas pela crise financeira internacional de meados de 2008 abalaram os resultados econômicos e do mercado de trabalho em 2009, ainda que melhores do que o temido no início da crise.

\section{IMPACTOS NO MERCADO DE TRABALHO E NAS CONDIÇÕES DE VIDA DA POPULAÇÃO}

Os indicadores de ocupação e desemprego e a produção e emprego industriais sofreram impacto negativo, enquanto outros elementos positivos se configuravam, como a trajetória de crescimento do rendimento médio real do trabalho e o nível do emprego formalizado, além da continuidade da queda da desigualdade de renda e da pobreza no país.

A literatura especializada enaltece as mudanças no mercado de trabalho e o desenvolvimento de redes de proteção social para a interpretação da melhoria dos principais indicadores de condições de vida no Brasil e queda da disparidade de rendimentos e da pobreza, particularmente pelo aumento expressivo da renda per capita real dos pobres, vivenciados nos anos 
2000 (HOFFMANN; NEY, 2008; HOFFMANN, 2009; NERI; MELO, 2008; FERREIRA; SOUZA, 2007; LAVINAS, 2007).

O comportamento das variáveis demográficas evidencia o aumento da expectativa de sobrevida da população, queda da fecundidade e aumento da longevidade, cuja interação tem levado a um maior crescimento da população idosa em relação aos demais grupos. Para isso concorreram as políticas sociais no âmbito da assistência social, entre elas:

- o Benefício de Prestação Continuada (BPC), instituído em 1993 pela Lei Orgânica da Assistência Social (LOAS) e destinado à população com 65 anos ou mais e a portadores de deficiência incapacitados para o trabalho, que possuem renda familiar per capita inferior a $1 \frac{1}{4}$ do salário mínimo (entre 1997 e 2003, o número de Benefícios de Prestação Continuada cresceu 648\%.);

- a Política Nacional do Idoso (PNI) aprovada em 1994, com o objetivo de assegurar ao idoso seus direitos sociais;

- a Política Nacional de Saúde do Idoso, elaborada pelo Ministério da Saúde em 1999, que determinou medidas preventivas e ampliou a assistência médica e o Estatuto do Idoso, em 2003.

Ao lado disso, após a segunda metade da década de 90, outras políticas de transferência de renda são implementadas no país e, mais recentemente, nos anos 2000, intensificam-se as políticas de transferências condicionadas ${ }^{1}$ de renda, destacando-se o Programa Bolsa Família. O Programa é voltado para pessoas que vivem com renda per capita abaixo da linha de pobreza (metade do salário mínimo) e atendeu 10,5 milhões de famílias em 2008, segundo dados do Ministério do Desenvolvimento Social.

\section{MERCADO DE TRABALHO E MUDANÇAS ESTRUTURAIS: TERCIARIZAÇÃO E TERCEIRIZAÇÃO}

Evidencia-se, sob outro aspecto, as mudanças positivas no mercado de trabalho, par-

\footnotetext{
1 Segundo a legislação, as transferências de renda são condicionadas à frequência escolar de crianças e adolescentes, acompanhamento do calendário vacinal e do crescimento e desenvolvimento para crianças menores de 7 anos, pré-natal das gestantes e acompanhamento das nutrizes. Além disso, na assistência social, há exigência de frequência no acompanhamento de ações socioeducativas para crianças e adolescentes de até 15 anos em risco ou retiradas do trabalho infantil, de acordo com o Ministério do Desenvolvimento Social.
} 
ticularmente a forte recuperação da taxa de participação e da ocupação total e do emprego assalariado formalizado, que contribuem para a manutenção da taxa de desemprego inferior a $10 \%$ ao ano na década. O movimento de terciarização (crescimento do setor serviços mais que proporcionalmente aos outros setores da economia) e terceirização (outsourcing) da ocupação se fez presente e pode ser visualizado pelo aumento das taxas de participação da mão de obra feminina no mercado de trabalho, pela migração de trabalhadores industriais para postos de trabalho no setor terciário, principalmente comércio e serviços em geral, e pelas modificações recentes sobre o mundo do trabalho, advindas dos processos globais de reorganização produtiva e organizacional. Ao lado da terciarização e da terceirização, tem-se o crescimento da ocupação na indústria até o ano de 2008, comparada à retração do período 1992-99.

No entanto, em meados de 2008, momento em que a economia brasileira estava em pleno crescimento, e o mercado de trabalho em recuperação, sobreveio a crise econômico-financeira internacional. Os efeitos mais severos concentraram-se na indústria de transformação; pois diante da redução dos níveis de confiança e da crise internacional, o setor industrial reduziu os níveis de produção e emprego.

Ao lado de fatores internos ligados à deterioração das expectativas e das restrições ao crédito privado, e da queda do comércio mundial, formaram-se os canais de transmissão da crise que, de acordo com análise publicada pelo IPEA (Instituto de Pesquisas Econômicas ligado ao Ministério do Planejamento) em fevereiro de 2009, motivaram a referida queda do desempenho do setor industrial. Como resultado desses movimentos, entre o fim de 2008 e o início de 2009, crescem as taxas de desemprego e cai o nível de utilização da capacidade instalada da indústria. A Pesquisa Industrial Mensal - IBGE - divulgou a retração do PIB industrial (- 4,5\% em 2009) e da capacidade utilizada da indústria (em agosto de 2008 era de 84,6\%, e em dezembro de 2008 e 2009 foram de 77,7\% e 79,6\%, respectivamente).

A exemplo de outros países, diversas medidas de caráter anticíclico foram adotadas pelo governo brasileiro a partir de dezembro de 2008. O objetivo principal foi o de contrapor a queda na demanda agregada originada pelo setor privado. Entre as principais medidas, destacam-se as seguintes:

- redução do Imposto sobre Produtos Industrializados (IPI) de produtos como automóveis e eletrodomésticos;

- ampliação de linhas de crédito para o mercado de carros usados;

- preservação dos investimentos, principalmente em infraestrutura, previstos no âm- 
bito do Programa de Aceleração do Crescimento (PAC) do Governo Federal.

Adicionalmente, o governo implementou ou ampliou medidas de cunho social que colaboraram para sustentar a demanda e os investimentos domésticos, especialmente no setor da construção civil, mesmo em face da crise externa. Entre as principais medidas destacam-se:

- os reajustes do salário mínimo e do Programa Bolsa Família (PBF);

- a ampliação do programa de seguro-desemprego;

- o pacote imobiliário.

O pacote imobiliário teve como referência a melhoria das condições de crédito (crescimento no volume e nos prazos de financiamento imobiliário nos segmentos de pessoas físicas e de pessoas jurídicas), a isenção de IPI para materiais de construção e os programas habitacionais, tanto para o sistema de mercado como para os de interesse social, com destaque para o Programa Habitacional Popular - Minha Casa, Minha Vida, cujo objetivo é atender as necessidades de habitação da população de baixa renda nas áreas urbanas².

O impacto mais importante da crise internacional no Brasil foi a interrupção do vigor do crescimento econômico, do quadro social brasileiro e do mercado de trabalho no primeiro trimestre de 2009. Entretanto, restabeleceu-se paulatinamente a normalidade nos períodos seguintes, demonstrando que a crise foi menos intensa e menos longa do que se previa no Brasil. Assim como em outros países emergentes, como a China e a Índia, a economia brasileira se mostrou mais resistente aos choques da crise internacional. Desta forma, nossa economia sofreu um impacto em termos de redução do produto nacional bruto e aumento do desemprego significativamente menor que outros países.

O emprego formal como evento almejado do mercado de trabalho seguiu a trajetória de crescimento da década. Dados da PME (Pesquisa Mensal do Emprego - IBGE) apontam que aproximadamente $50 \%$ da população ocupada nas regiões metropolitanas do país estavam formalizadas entre janeiro e setembro de 2010 , contra $47 \%$ do ano de 2007 . Os microdados da

2 De acordo com o Ministério das Cidades, o programa funciona por meio da concessão de financiamentos a beneficiários organizados de forma associativa por entidade organizadora (associações, cooperativas, sindicatos, entre outros), com recursos provenientes do Orçamento Geral da União - OGU, aportados ao Fundo de Desenvolvimento Social - FDS, podendo ter contrapartida complementar de estados, do Distrito Federal e dos municípios. 
PNAD (Pesquisa Nacional por Amostra de Domicílios - IBGE) corroboram o fato. Em 2009, os empregados com carteira de trabalho assinada (um indicador de formalização das relações de trabalho) representavam 39\% do total de ocupados no país, contra 38\% em 2007. A demanda de mão de obra permaneceu centrada em faixas etárias mais velhas (mais de 40 anos) e mais escolarizadas (mais de 8 anos de estudos).

O detalhe foi a queda na taxa de crescimento do nível das ocupações no período 20082009 frente ao crescimento médio da década como um todo, segundo a Pesquisa Mensal de Emprego. Os setores mais atingidos em termos de redução dos postos de trabalho foram os da indústria, transporte e serviços coletivos. Os que sentiram menor impacto foram os serviços domésticos e a administração pública. Outro indicador sintético do mercado de trabalho, a taxa de desemprego, aumentou em 2009, embora tenha iniciado uma recuperação em 2010.

Merecem destaque os indicadores que seguiram seu curso favorável nos anos 20082010, de acordo com a Pesquisa Mensal de Emprego, pelos quais se pode perceber o restabelecimento do mercado de trabalho e da situação social do país: os rendimentos médios reais dos trabalhadores mantiveram crescimento em 2009, iniciado no ano de 2004. Após a queda dos rendimentos médios reais do trabalho até o ano de 2004, tem-se um período de melhoria que significou um crescimento de 12,2\% na década de 2000 como um todo (2001-2009) e um incremento de $2,5 \%$ entre 2008 e 2009.

O salário mínimo manteve-se em processo de valorização até 2010, segundo o DIEESE - Departamento Intersindical de Estatística e Estudos Socioeconômicos, e acumulou um aumento real de 99\% de julho de 1994 a dezembro de 2008. De 2003 a 2009 o salário mínimo acumulou aumento real de 54\%, e nos anos recentes, as informações são as que seguem: seus valores nominais eram de $\mathrm{R} \$ 415,00, \mathrm{R} \$ 465,00$ e $\mathrm{R} \$ 510,00$, movimentando-se de forma real e ascendente em 4\%, 5,8\% e 6\%, nos anos de 2008, 2009 e 2010, respectivamente.

Por fim, restabeleceu-se a queda da pobreza e da desigualdade de renda, com melhoria no posicionamento no ranking do Índice de Desenvolvimento Humano, publicado pelo PNUD. A Tabela 2 abaixo expõe essas informações. Reconhece-se, no entanto, que o Brasil é hoje um país desigual; ainda que o índice de Gini mostre a redução da desigualdade de renda pós-2001, o país está em situação pior que outros países latino-americanos, como México, Uruguai ou Venezuela, e muito distante de países da Organização para a Cooperação e Desenvolvimento Econômico (OCDE). 
TABELA 2 - INDICADORES DE POBREZA, DESIGUALDADE DE RENDA E DESENVOLVIMENTO HUMANO

\begin{tabular}{|c|c|c|c|c|c|c|c|c|c|}
\hline & 2001 & 2002 & 2003 & 2004 & 2005 & 2006 & 2007 & 2008 & 2009 \\
\hline Extrema pobreza ( $\%$ pop)* & 15,28 & 13,99 & 15,20 & 13,20 & 11,49 & 9,44 & 8,65 & 7,57 & 7,28 \\
\hline Pobreza ( $\%$ pop $)^{* *}$ & 35,17 & 34,40 & 35,79 & 33,70 & 30,82 & 26,75 & 24,24 & 22,59 & 21,42 \\
\hline Índice de Gini & 0,596 & 0,589 & 0,583 & 0,572 & 0,569 & 0,563 & 0,556 & 0,548 & 0,543 \\
\hline IDH & - & nd & 0,788 & 0,792 & 0,800 & 0,808 & 0,813 & - & - \\
\hline Posição no ranking do IDH & & $63^{\circ}$ & $68^{\circ}$ & $69^{\circ}$ & $70^{\circ}$ & $75^{\circ}$ & $75^{\circ}$ & & $73^{\circ}$ \\
\hline
\end{tabular}

FONTE: IPEADATA e PNUD.

NOTA: * Percentual de pessoas na população total com renda domiciliar per capita inferior à linha de extrema pobreza (ou indigência, ou miséria). A linha de extrema pobreza é uma estimativa do valor de uma cesta de alimentos com o mínimo de calorias necessárias para suprir adequadamente uma pessoa, com base em recomendações da FAO e da OMS; ${ }^{* *}$ Percentual de pessoas na população total com renda domiciliar per capita inferior à linha de pobreza. A linha de pobreza é o dobro da linha de extrema pobreza.

\section{CONSIDERAÇÕES FINAIS: CONSTRANGIMENTOS AO CRESCIMENTO ECONÔMICO SUSTENTADO AINDA PREVALECEM}

Diante disso, se há que se considerar que as transformações econômicas, sociais e de trabalho foram muito expressivas e o país observou respostas positivas no enfrentamento da crise internacional, por outro lado, persistem constrangimentos significativos na economia brasileira.

Em primeiro lugar, a política econômica brasileira tem se sustentado em juros domésticos altos (taxa básica SELIC) face à urgência de financiamento do setor público. Dados do Banco Central do Brasil apontam que o estoque da dívida líquida do setor público (DLSP) alcançou R \$ 1,41 trilhão em agosto de 2010 ou, em proporção do PIB, 41,4\%, contra 36\% em 2008. O resultado primário do Governo, pelo conceito de NFSP - Necessidade de Financiamento do Setor Público, foi de redução do superávit, 2,1\% do PIB contra 5,2\% - valores acumulados janeiro/agosto 2008 e janeiro/agosto 2010. Para o mesmo período, o déficit nominal que representava $0,9 \%$ do PIB passa para 3,3\% do PIB. A despesa pública da União para o período de janeiro/julho de 2010 representa 30,4\% do PIB, sendo 24,1\% referentes às suas despesas correntes, o que demonstra uma baixa capacidade de investimento do setor público brasileiro.

Essa situação fiscal coexiste com uma carga tributária que se constitui numa das mais altas entre os países em desenvolvimento: 35\% do produto nacional bruto em 2009. É muito provável que o Brasil esteja atingindo um limite máximo em termos de carga tributária além do qual o peso dos tributos poderá gerar impactos negativos em termos do crescimento econômico.

Em segundo lugar, a utilização da poupança externa, especialmente através de investimentos externos em carteira-portfólio, é incentivada pelas altas taxas de juros internas, 
valorizando a moeda local, o real. A apreciação da moeda local abre possibilidades de comprometimento dos investimentos produtivos e geradores de emprego, particularmente aqueles destinados às exportações de produtos de maiores valores agregados. Cabe mencionar que, por outro lado, ocorre a descoberta e a exploração das reservas de petróleo e gás natural nas bacias do pré-sal brasileiro, diante de um contexto geoeconômico em que a dinâmica da economia chinesa impulsiona os preços e as exportações de commodities primárias, favorecendo as expectativas de crescimento futuro da economia brasileira.

A despeito dos mecanismos utilizados pelo Brasil para o amortecimento da crise internacional recente e seus efeitos menos contundentes no mercado de trabalho e nas condições de vida da sua população, é preciso ponderar pelos problemas que ora persistem na economia brasileira, que em sua essência parecem estar na responsabilidade fiscal, nas taxas domésticas de juros e nas práticas que repercutem na apreciação cambial.

\section{REFERÊNCIAS}

HOFFMANN, R.; NEY, M. G. A recente queda da desigualdade de renda no Brasil: análise de dados da PNAD, do Censo Demográfico e das Contas Nacionais. Econômica, v. 10, p. 7-39, 2008.

HOFFMANN, R. Desigualdade da distribuição da renda no Brasil: a contribuição de aposentadorias e pensões e de outras parcelas do rendimento domiciliar per capita. Economia e Sociedade, v. 18, p. 213-231, 2009.

NERI, M. C.; MELO, M. C. Miséria e a nova classe média na década da igualdade. Rio de Janeiro: FGV, 2008. Disponível em: <http://www3.fgv.br/ibrecps>.

FERREIRA, C. R.; SOUZA, S. C. I. As aposentadorias e pensões e a concentração dos rendimentos domiciliares per capita no Brasil e na sua área rural: 1981 a 2003. Revista de Economia e Sociologia Rural, Rio de Janeiro, v. 45, p. 985-1011, out./dez. 2007.

LAVINAS, L. Gasto social no Brasil: programas de transferência de renda versus investimento social. Ciência e Saúde Coletiva, Rio de Janeiro, v. 12, p. 1463-1476, nov./dez. 2007. 